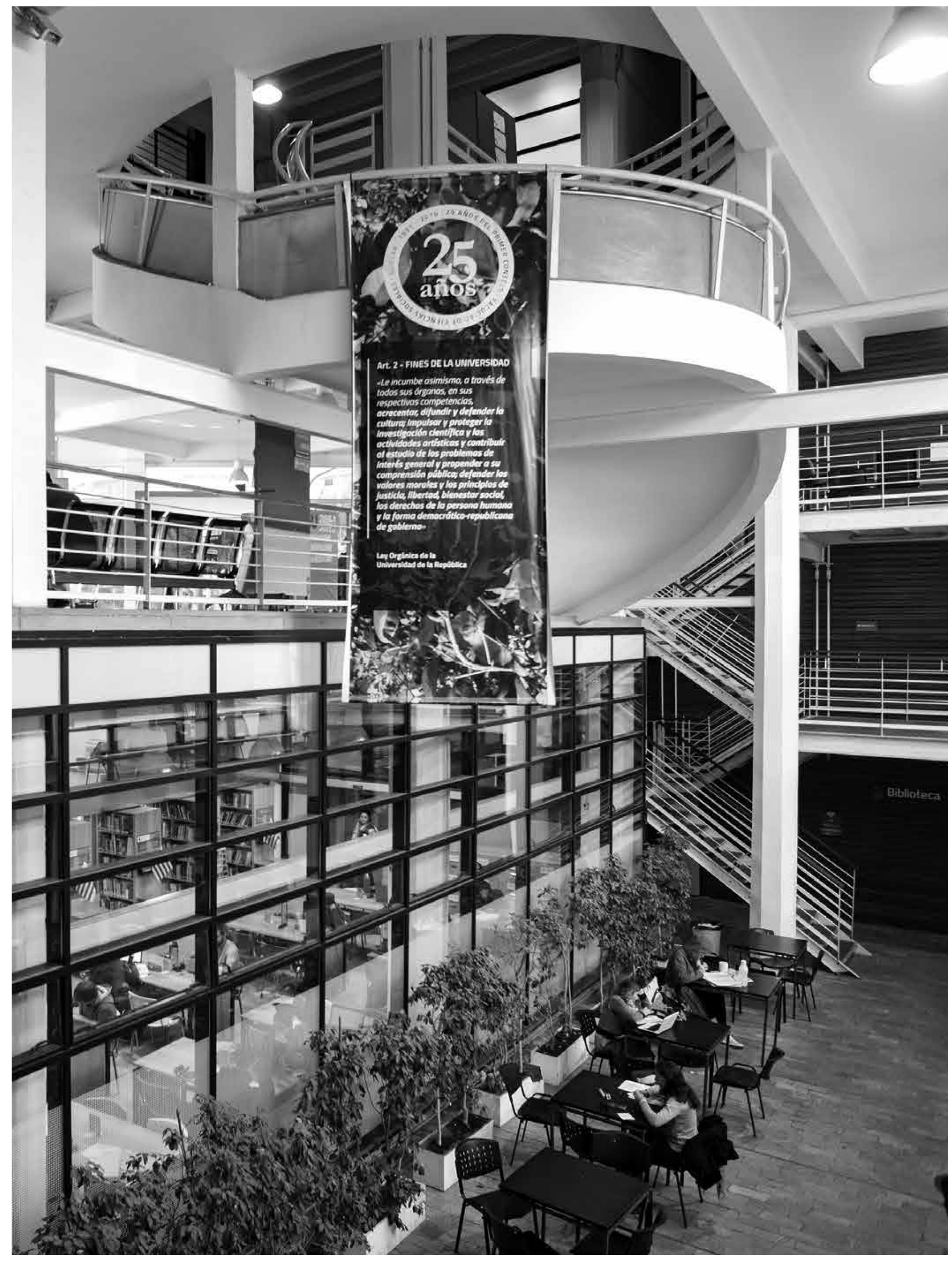




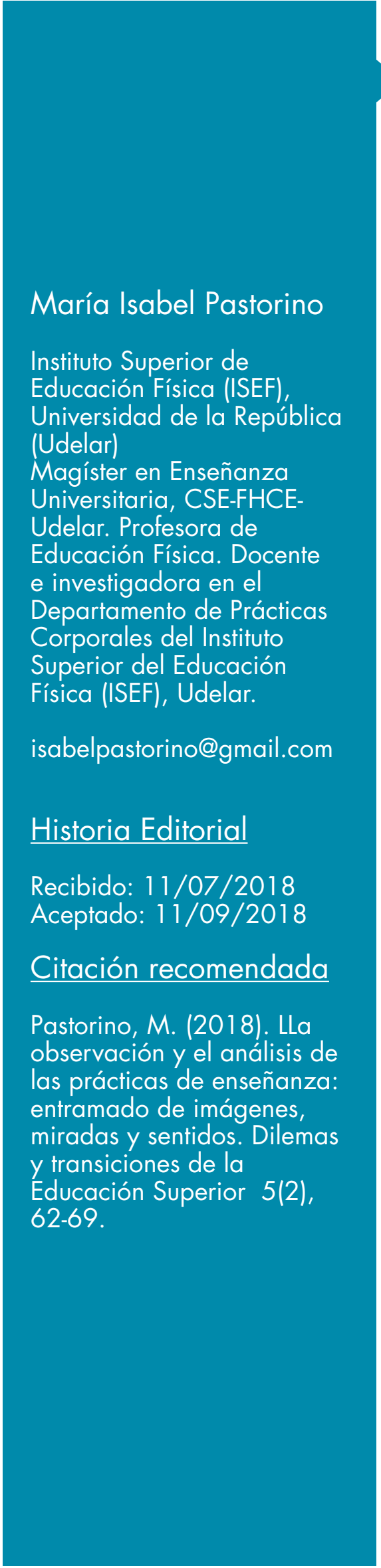

\section{La observación y el análisis de las prácticas de enseñanza: entramado de imágenes, miradas y sentidos}
Observation and analysis of teaching practices: a web of images, perspectives, and senses

\section{Observação e análise de práticas de ensino: entrelacamento de imagens, olhares e sentidos}

La mirada de un fotógrafo, como la de cualquier individuo, está marcada por las condiciones subjetivas desde donde se observa el mundo. Así como dicen que un escritor en definitiva siempre escribe el mismo libro, un fotógrafo siempre mira desde un mismo lugar o realiza, de alguna manera, la misma fotografía.

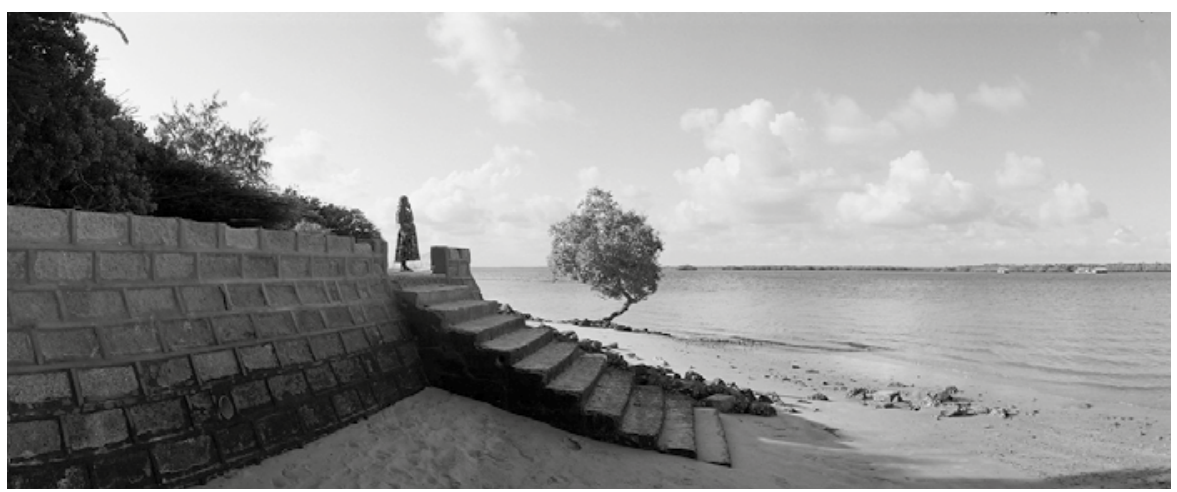

Fotografia de Guilherme Botelho, Sheilla (2012).

Resumen

Este artículo trata sobre la observación y análisis de las prácticas de enseñanza. Aunque el trabajo se centra en los espacios de formación en la educación superior, en particular en las prácticas docentes, se asume que, a pesar de las distancias con otros escenarios pedagógicos, en cualquier caso el ejercicio de analizar las prácticas presenta ciertos rasgos comunes que de forma compleja se asemejan.

Se toman como base algunos de los alcances obtenidos en la tesis realizada para obtener el título de magíster de la Maestría en Enseñanza Universitaria de la Comisión Sectorial de Enseñanza (CSE) y de la Facultad de Humanidades y Ciencias de la Educación (FHCE) de la Universidad de la República (Udelar). En ella se estudió la tarea de la 
orientación y su configuración en la práctica docente de la Licenciatura en Educación Física del Instituto Superior de Educación Física (ISEF), Udelar. De este estudio se desprenden evidencias que dan cuenta de los elementos más importantes que inciden en la observación y el análisis de las prácticas de enseñanza asumidas en la función de la orientación. Se pudo reconocer, además, la complejidad que implica asumir esta función con estudiantes, en un espacio que se constituye a partir de un encuentro con otro, pero también $y$ necesariamente, con uno mismo. Escenario marcado por el diálogo de imágenes y miradas sobre lo que acontece en un tiempo dado, espacio de formación que se construye a partir de la intersubjetividad.

\section{Palabras claves:}

Formación, práctica docente, observación y análisis de las prácticas, orientación.

\section{Abstract}

This article deals with observation and analysis of teaching practices. This work focuses mainly on teaching practicum in higher education settings. In spite of the differences this has regarding other pedagogical scenarios, it is assumed that the exercise of analyzing such practices has certain common features, which are complexly alike.

This article is based on some findings from the thesis submitted for a Master's degree in University Teaching offered by Comision Sectorial de Enseñanza (CSE, Sectoral Commission of Education) and Facultad de Humanidades y Ciencias de la Educación (FHCE, School of Humanities and Education Sciences) of Universidad de la República (UdelaR, University of the Republic). The thesis has studied the task of orientation and how it was shaped during teaching practice in the Physical Education program of the Instituto Superior de Educación Física (ISEF, Higher Institute of Physical Education), Udelar. It also showed evidence of the most important elements influencing the observation and analysis of teaching practices assumed in the task of orientation. It also recognized the complexity of assuming this task with students in a space that implies an encounter with each other, but also and necessarily, with oneself. This scenario is characterized by a dialogue in images and perspectives on the events unfolding during a given time, a training space that builds from intersubjectivity.

\section{Keywords:}

Training, teaching practice, observation and analysis of practices, orientation.

\section{Resumo}

Este artigo trata da observação e análise de práticas de ensino. Embora o trabalho esteja centrado nos espaços de formação de educação superior, em particular nas práticas docentes, assume-se que, apesar das distâncias de outros cenários pedagógicos, o exercício de análise das práticas apresenta características comuns que, de forma complexa, são semelhantes em qualquer cenário.

A base é formada por alguns dos resultados da tese realizada para obter o título de mestrado em Ensino Universitário da Comissão Setorial de Ensino (CSE) e da Faculdade de Humanidades e Ciências da Educação (FHCE) da Universidad de la República (Udelar). Na tese foi estudada a tarefa da orientação e sua configuração na prática docente da Licenciatura em Educação Física do Instituto Superior de Educação Física (ISEF), da mesma Udelar. Deste estudo saem evidências que dão conta dos elementos mais importantes que incidem na observação e na análise das práticas de ensino assumidas na função da orientação. Foi possível reconhecer também a complexidade implicada ao assumir a função perante alunos em um espaço constituído a partir de um encontro com o outro, mas também, e necessariamente, consigo mesmo. Cenário marcado pelo diálogo de imagens e olhares sobre o que acontece em um determinado tempo, um espaço de formação que é construído a partir da intersubjetividade.

\section{Palavras-chave:}

Formação, prática docente, observação e análise de práticas, orientação.

\section{Introducción}

En este trabajo se presentan algunos de los puntos esenciales obtenidos en la tesis de maestría La configuración de la orientación en la práctica docente universitaria: el caso del ISEF, y se incorpora la perspectiva de la observación en el arte, en el intento de revelar las prácticas de enseñanza desde otro enfoque. La investigación mencionada propone un análisis de la función de la orientación situada en el contexto de la unidad curricular Práctica Docente I (Prado I) del tercer año de la Licenciatura en Educación Física del ISEF (Udelar). El estudio se desarrolló en torno a ciertos interrogantes: ¿cómo se compone la orientación?, ¿qué saberes la configuran?, ¿cuáles son las representaciones de los actores?, ¿de dónde provienen?, ¿qué identidades o tradiciones se evidencian?, ¿qué tipo de saberes habilitan?, ¿qué alcance tiene la reflexión? 
Se emplearon diferentes técnicas: estudio de documentos (plan de estudios, plan de la unidad curricular Práctica Docente, trabajos de los estudiantes, entre otros), entrevistas en profundidad a los docentes y análisis del material textual extraído de las grabaciones de audio de las orientaciones realizadas. El material relevado se analizó a la luz de categorías ex ante $\mathrm{y}$ emergentes, y fue posteriormente triangulado a los efectos de llegar a las conclusiones. Estas se presentaron a partir de tres ejes:

1. Posibles relaciones entre los tipos de saberes que predominan en la orientación y las tendencias de los docentes sobre identidades y tradiciones.

2. Concepciones de educación y de educación física escolar que subyacen.

3. Naturaleza y alcance de la reflexión que se alcanza en la orientación.

A partir del análisis realizado, se pudieron reconocer algunos elementos que cobraron especial relevancia, de los cuales se destacan: los supuestos básicos subyacentes ${ }^{1}$ y la postura del docente con relación a estos; el vínculo docenteestudiante y su incidencia en el alcance de la reflexión; la relación teoría-práctica que predomina en la orientación; los saberes que circulan y que se jerarquizan en función de lo que se observa, y las trayectorias de vida de los docentes, las identidades y tradiciones que en forma compleja encarnan (Pastorino, 2015).

En este artículo se abordan aspectos que se vinculan con la figura de la orientación, específicamente lo que concierne a la observación y el análisis de las prácticas de enseñanza. Se toman, además, aportes y reflexiones provenientes del campo artístico sobre la experiencia de la observación, la plasticidad del gusto, el criterio es- tético, la relación imagentiempo, entre otros elementos, con la intención de presentar otra perspectiva de exploración sobre el tema.

\section{La experiencia de la observación}

En el Diccionario de la lengua española (RAEASALE, 2014), observación significa 'acción y efecto de observar', mientras que observar se define como 'examinar atentamente'.

En la observación, en términos generales, se coloca la mirada sobre algo que llama la atención, ya sea para conocer, comprender, valorar, descalificar, describir o explicar. En cualquier caso, la mirada siempre parte de uno mismo, es decir, está marcada inevitablemente por la subjetividad; se podría señalar, incluso, que lo que vemos y lo que omitimos ver ya implica de alguna manera un nivel de interpretación de la realidad observada.

En algunos ámbitos de la cultura, como por ejemplo el arte o la arquitectura, la observación en tanto crítica ha generado profundos debates sobre temas como la plasticidad del gusto o el relativismo estético, mostrando cómo ciertas manifestaciones que en un momento de la historia no fueron llamadas arte, más tarde fueron consideradas parte de un movimiento renovador e impulsor de nuevas corrientes o formas artísticas.

En ese sentido, Gombrich (2004: 184186) señala que ha habido intentos de describir el arte como «una tecnología encaminada a conseguir determinadas satisfacciones, la creación de esa experiencia estética sobre la que tanto se escribe», y agrega que, de ser cierta esta afirmación, «nuestras reacciones espontáneas ante las obras de arte serían el único y seguro criterio de su calidad». Sin embargo, explica el autor, sabemos por la his- toria del arte, y a partir también de nuestra propia experiencia, que han existido y existen muchas personas a quienes, por ejemplo, nunca les agradaron Mozart o Rembrandt y que no supieron apreciar sus maravillosos logros. Por otra parte, el autor insiste en considerar que la creencia que sostiene la objetividad de los cánones artísticos no queda necesariamente refutada por la incuestionable subjetividad de los gustos, ya que aquellos a quienes no les interese la ópera no se dedicarán a juzgarla. Para la mayoría de la gente, expresa el autor, gustar es la condición previa para apreciar: «solamente en caso de que determinados tipos de arte les prometan placer, harán el esfuerzo de prestar atención a la obra». No obstante, plantea la salvedad de que el crítico profesional puede y debería ser capaz de apreciar logros artísticos en un autor o en una época que no le atraiga; pero advierte que esa apreciación «fría» de lo que no nos gusta «es un sustituto deficiente de la experiencia que una obra de arte puede brindarnos", ya que, de algún modo, se trata de suspender la crítica y someterse a la obra de arte explorando su complejidad.

Dicha experiencia está íntimamente relacionada con el amor. Existe un componente de abandono inicial en dicha reacción que quizá pueda compararse con lo que el psicoanálisis llama transferencia. [...] Si simplemente intentamos eliminar los prejuicios en nuestro acercamiento, nunca descubriremos lo que la obra de arte puede ofrecernos.

Cabe preguntarse a partir de este planteo, dejando claro que no se pretende establecer una igualdad de carácter estricto entre las prácticas pedagógicas y las prácticas artísticas, ¿qué límites y posibilidades presentan las prácticas de enseñanza para ser ob-

1 En el planteo de Lores Arnaiz (1986: 138), según Alvin Gouldner, se distinguen dos grandes tipos de supuestos básicos subyacentes (SBS): por un lado, hipótesis acerca del mundo, creencias acerca de la realidad, identificadas a veces con supuestos ontológicos; y por otro, supuestos acerca de ámbitos más limitados, concepciones acerca del hombre, de la realidad, incluso de una profesión. Se definen como básicos porque no constituyen fundamentos teóricos, sino que su origen es más profundo, y subyacen porque no son explícitos; de alguna manera, permanecen ocultos. 
servadas y estudiadas desde una perspectiva estética y/o científica?, ¿cuáles podrían ser los puntos de conexión entre la crítica del arte y la observación de las prácticas de enseñanza? Al respecto parecería pertinente detenernos a reflexionar sobre la posibilidad de que así como nuestros prejuicios, creencias, gustos racionales o no y supuestos conscientes o no condicionan nuestro acercamiento a la experiencia que nos puede proporcionar el arte, del mismo modo podría estar determinada nuestra experiencia a la hora de mirar las prácticas de enseñanza que intentamos analizar.

Podríamos señalar además que, en algún sentido, las prácticas de enseñanza en su construcción también están determinadas por una "estética de clase», en ella se produce una organización del tiempo, del espacio, del ritmo, de las voces, que impacta sobre los protagonistas de dicha escena (alumnos y docentes), pero también sobre quien esté circunstancialmente observando. En el campo de la educación física, sin la intención de establecer generalizaciones, las prácticas de enseñanza poseen un singular lenguaje en cuanto a su estructura, la utilización del tiempo y del espacio, con un alto contenido visual; pueden involucrar trabajo individual o en pequeños o grandes grupos; pueden organizarse en filas, columnas, rondas o en dispersión; los movimientos pueden ser sincrónicos o asincrónicos, entre otras variantes. Las impresiones que eventualmente se generan en este nivel primario de observación podrían estar condicionando el gusto o disgusto que habilita o inhabilita la condición previa de la atención para dar lugar, posteriormente, a un análisis profundo sobre una práctica determinada. En ese sentido acordamos con la idea que sostiene Weil (2007: 154) de que «la atención se halla ligada al deseo. No a la voluntad, sino al deseo. $O$, más exactamente, al consentimiento».

\section{Revelar las prácticas de enseñanza}

En las instancias en las que se analizan prácticas de enseñanza, los sujetos quedan expuestos, tal como nos dice Edelstein (2011). Para los docentes, sus prácticas significan poner el cuerpo, estar al frente, sostener y sostenerse, exponer y exponerse. Esto provoca, según la autora, una sensación de fragilidad o de vulnerabilidad que se agudiza cuando ingresa al aula una presencia no habitual.

El que presenta su práctica manifiesta, muestra, expone; sin embargo, para quien observa también existe un cierto nivel de exposición. Desde el instante en que coloca su mirada, tal como mencionábamos, podrá gustarle o no lo que observa y, desde ese momento, quedará sometido a esta experiencia. Si le gusta (como condición previa), dará cabida a la apreciación y, a partir de allí, posiblemente elaborará el análisis. Si le disgusta, podrá, o bien intentar eliminar sus prejuicios para realizar un análisis distante, "frío», al decir de Gombrich (2004), o podrá estar dispuesto a poner sus prejuicios a prueba y dialogar y escuchar los argumentos que puedan conducir a la refutación de estos. En este caso el diálogo de miradas tendría la oportunidad de provocar un análisis profundo y fino, revelando la práctica que se observa.

Pero ¿qué significa, en el terreno de la enseñanza, poner los prejuicios y creencias a prueba?, ¿cómo se puede construir ese diálogo honesto entre quien observa y quien es observado? Resulta interesante detenerse a reflexionar sobre la mirada inicial que se coloca en las prácticas de enseñanza y las primeras impresiones que esta genera en quienes observan. En los docentes protagonistas de esta investigación y en los diálogos registrados, fue dificil encontrar evidencias sobre este nivel primario, espontáneo e inmediato de la experiencia de la observación. Solo se pudo constatar una aproximación a esta perspectiva en uno de los docentes, quien, al inicio de dos de los análisis registrados, expresaba: "Vi esta clase, y me imaginé muchas cosas que sucedieron la clase pasada", "Hoy vi una clase que me pareció que valió la pena, más allá de todo lo que haya pasado [...]».
Tarkovski (2017: 66) explica, en relación con la observación en el arte, que lo más frecuente es que quien interpreta una obra centre su atención en un campo determinado para ilustrar en él su propia posición, y agrega que en muy pocas ocasiones se parte de un contacto vivo o inmediato con la obra.

[...] para una recepción así, pura, haría falta una capacidad fuera de lo común para llegar a un juicio original, independiente, inocente por llamarlo de algún modo; [...] el hombre normalmente busca confirmación de la propia opinión en el contexto de ejemplos y fenómenos que ya conoce, por lo que juzga las obras de arte por analogía con sus ideas subjetivas o con experiencias personales.

En el análisis realizado por estos docentes, y a medida que este transcurre, se pudo observar que los saberes que rápidamente cobran una mayor presencia son los de orden didáctico: «La planificación, la formulación de los objetivos, el recorte, y la vigilancia del saber seleccionado a enseñar, etc.; y por otra parte los contenidos específicos del área de conocimiento, en este caso los de la educación física escolar» (Pastorino, 2015: 82). Es posible interpretar, más allá de la pertinencia de la presencia de estos saberes e intentando arrojar otra perspectiva sobre el tema, que la rápida intervención de los docentes sobre temas conocidos por ellos podría significar, en algún sentido, la búsqueda de confirmación de su posición en el análisis que realizan a partir de fenómenos y contextos que ya conocen.

Para Ferry (en Souto, 2017: 161), el análisis «se funda en lo imprevisible y en lo no dominable, es decir, en lo desconocido e incierto». Para el autor, el ejercicio del análisis es el que asegura los procesos de formación: «la experiencia solo tendrá efectos transferenciales cuando se lleve a cabo un trabajo de elucidación que dé lugar a tomas de conciencia, a una movili- 
zación de representaciones y expectativas».

El desafio que se presenta a la hora de observar y analizar las prácticas de enseñanza es el de ir más allá de las imágenes impresas en la memoria personal y colectiva acerca de las representaciones sobre lo conocido y superarlas.

La movilización de imágenes, paradójicamente, podría darse precisamente a partir de habilitar una primera mirada espontánea, "viva» sobre lo que se observa, exponiéndose a la experiencia estética que produce la observación, dejando que las prácticas se revelen y las impresiones se renueven, poniendo a prueba los prejuicios y experiencias conocidas a partir de un intercambio de miradas genuinas, dando lugar a un diálogo honesto.

Este planteo, vale aclarar, no desestima en ningún sentido el análisis con ayuda de referentes teóricos, sino que señala la importancia de revisar la forma en que nos aproximamos a la experiencia de la observación, y propone hacerlo desde otras perspectivas en el intento de comprender la realidad observada, como dice Souto (2017: 161), a partir de «un pensar que no separa el sentir».

\section{El tiempo en diálogo con las imágenes}

Como ya hemos mencionado, fue complejo constatar en este estudio expresiones que dieran cuenta del impacto que produce el primer acercamiento a la clase observada; sin embargo, se registraron evidencias que dan cuenta de las impresiones que provocan en los observadores el tiempo, el ritmo y el espacio, elementos claves en toda experiencia de carácter estético. A modo de ejemplo se presentan las siguientes citas tomadas del estudio: "Traten de utilizar el mejor espacio posible»; «¿Cómo piensan el tiempo de la clase?»; «ese era un buen momento porque tenían un buen espacio»; "yo pensaría en la secuencias de clases, de propuestas»; «jugaron como diez minutos cada grupo».
Aunque estos elementos, de alguna manera, se relacionan con el sentido estético en términos generales, en los hechos no se aborda de manera explícita esta perspectiva. En estas citas, interpreto, se abordan el tiempo, el ritmo y el espacio, discutiendo el buen uso de estos en función de las concepciones acerca de la buena práctica. Cabe preguntarse: ¿de dónde proviene la idea de buena práctica en relación con estos elementos?

Edelstein (2011: 203) señala que los registros que se realizan sobre la clase observada no devienen de una mirada despojada de teoría, sino que se relacionan generalmente con «estructuras de diseño que operan como representaciones anticipadas organizando los datos en alguna medida inconexos según se presentan en la inmediatez». En este caso, tal como dice la autora, la formación de docentes sobre la estructura temporal de la clase, orientada por la llamada agenda clásica de la didáctica, imprime con fuerza imágenes que se le asocian, y estas se constituyen en una especie de «buscador» que funciona como un filtro, tanto en el momento de observar como en el de analizar lo registrado.

Es decir que las imágenes preexistentes y las representaciones que poseen los docentes sobre la correcta estructura temporal de la clase, según lo que dictan la didáctica clásica o la experiencia propia, entre otros aspectos, estaría operando como un filtro que impide ver estos elementos desde otros ángulos, aristas o perspectivas; las que se refieren específicamente a observar la clase como un suceso único, con su propio ritmo, espacio y tiempo, producto de los acontecimientos que se suceden de forma espontánea $y$, en cierto sentido, impredecibles; en suma, con una armonía propia (en su sentido estético).

En esta clave de análisis y en relación con la observación de una obra de arte, Tarkovski (2017: 131) realiza un planteo similar sobre el impacto que provoca la imagen en el observador. Dice el autor:
Una imagen lleva al espectador a una vivencia simultánea de sentimientos tremendamente complejos, contradictorios y en algunos casos que se excluyen mutuamente. [...] el hombre indefectiblemente prefiere una cosa a otra, elige y sitúa la obra de arte en el contexto de su experiencia personal, sin querer, actúa de forma pragmática, es decir, defendiendo en lo grande y en lo pequeño su propia verdad, así también trata a la obra de arte según su propio arbitrio. Lo sitúa en el marco de sus propias conexiones vitales y lo une con determinadas fórmulas de pensamiento.

Reconocer este nivel de implicancia, que se da inevitablemente en toda observación y análisis que realizamos, podría dar lugar a nuevas formas y alternativas de concebir las clases, como dice Edelstein (2011: 203), como configuraciones abiertas. Se genera además la necesidad de revisar y provocar un cambio en cuanto a los registros de la observación (cuadernos de campo, grabaciones, filmaciones, entrevistas a los docentes protagonistas, estudio de documentos que se relacionan con la planificación y el diseño de la clase observada, articulación con la teoría, entre otros) atendiendo a la flexibilidad o pluralidad metodológica de estos, asumiendo que en ningún caso los registros podrán dar cuenta de la complejidad observada. Sin embargo, para la autora «los registros exhaustivos, densos, permiten un giro en ese sentido. La lectura y re-lectura de los mismos será la base para la identificación de categorías asociadas específicamente a las situaciones objeto de estudio".

Otro de los elementos, que se relaciona con el tiempo y su articulación con la observación, los registros y el análisis, es el enlace entre estos momentos. La clase y su observación se dan en simultaneidad, el registro en ocasiones también, y en otras, con posterioridad. El análisis y la discusión sobre los acontecimientos, en el sentido amplio, acontece una vez que el tiempo está sellado, Tarkovski (2017). 
Es decir, no se puede volver sobre los hechos si no es a través del recuerdo, intentando recuperarlos.

En la investigación a la que hace referencia este artículo se pudieron reconocer momentos en los que la reflexión se daba, según el planteo de Schön ${ }^{2}$ (1992; 1998), en la acción. Tal como se puede apreciar en los siguientes ejemplos, los protagonistas evocan pensamientos y reflexiones que se dieron mientras estaban conduciendo su clase: «Me di cuenta de que no era el momento de decirles nada»; "Cuando vi ese desorden que vi, vi como que todos iban al mismo arco [...] entonces fue ahí que paramos y dimos la estrategia».

Este nivel fue muy poco frecuente en los registros obtenidos, en él se reflexiona dentro de la acción presente, in situ. Para el autor, cuando alguien reflexiona desde la acción, "se convierte en un investigador en el contexto práctico» (Schön, 1998: 72).

Con respecto al nivel de la reflexión sobre la acción, es decir posfacto, en la que se reflexiona sobre los hechos del pasado inmediato, se pudo constatar una presencia más dominante. En este caso las reflexiones hacen referencia a errores o aciertos que se dieron en la clase que concluyó. Las siguientes citas extraídas del estudio constituyen algunos ejemplos: «Creo que se dio lo que planteábamos, o sea, que las actividades estaban acordes a ese saber, de expresión»; "La idea es que evaluara yo, pero ta, se me hizo dificil evaluar, [...] capaz igual hay que hacer otra evaluación, no sé».

La presencia predominante de expresiones, comentarios y reflexiones en esta categoría (reflexión sobre la acción) podría relacionarse precisamente con la idea de que el análisis que se realiza se enfoca en los hechos que ya acontecieron, que es necesario evocar, reconstruir acontecimientos que ya pasaron; y esto representa en el plano del análisis todo un desafio, entre otros elementos porque dicha reconstrucción, tal como nos dice Andreozzi (1996), «nunca es fiel al a la realidad».

Desde esta lógica de abordaje sobre el tiempo y siguiendo con los aportes que propone la observación del arte, retomamos el planteo de Tarkovski (2017: 77), quien se pregunta al respecto:

Pero, ¿qué significa el «pasado»? [...]. Lo presente se nos escapa y desaparece, como el agua entre las manos. Su peso material no lo adquiere sino el recuerdo. [...] Pues para el hombre, el tiempo no puede desaparecer sin dejar huella, ya que para él no es sino una categoría subjetiva, interior. El tiempo que hemos vivido queda fijado en nuestras almas como una experiencia forjada en el tiempo.

La observación y el análisis de las prácticas de enseñanza se ven desafiados al juego que proponen el tiempo y las imágenes a partir del registro de imágenes 区las preexistentes a la clase observada y las que esta proporciona en tiempo presente区, de los recuerdos sobre los acontecimientos que concluyeron y de los recuerdos sobre otras experiencias pasadas que se vinculan con el observador y con el observado. Son afectados en diversas formas por el tamiz de la memoria, producto de la historia individual y colectiva.

Esto, a su vez, se relaciona estrechamente con el concepto de habitus de Bourdieu (1980: 88), que nos plantea que es este el que "asegura la presencia activa de experiencias pasadas, registradas en cada organismo bajo la forma de esquemas de percepción, de pensamiento y de acción»; garantizando con más fuerza que todas las normas y reglas explícitas la permanencia y persistencia de las prácticas a través del tiempo. Y es que para construir nuevas formas de mirar y de pensar las prácticas de enseñanza, señala Edelstein (2011), es necesario modificar esquemas de acción y habitus.

\section{Algunas reflexiones finales}

En este artículo se trabajó el tema de la observación y el análisis de las prácticas de enseñanza, haciendo foco en la experiencia de la observación y la forma en que esta puede determinar el análisis.

Los elementos que se abordan se vinculan con la investigación realizada sobre la función de la orientación; en particular, a la hora de observar y analizar las prácticas de enseñanza, en articulación con la perspectiva que proporciona el arte acerca de la experiencia de la observación desde una clave estética, a partir de la relación que se establece entre algunos de sus elementos, la imagen, el ritmo y el tiempo.

En la investigación mencionada se pudieron constatar otras aristas que inciden de manera relevante en la tarea de la orientación de las prácticas de formación docente:

- Las creencias y supuestos que tienen los docentes orientadores sobre la buena orientación y la forma en que estos determinan, por ejemplo, la idea de no moldear, de no incidir en el pensamiento de los estudiantes.

- La relación practicantedocente y la forma en que esta habilita o inhabilita una reflexión honesta y profunda sobre las prácticas de enseñanza.

- La gestión de las voces y de los silencios, en relación con los tiempos en que hacen uso de la palabra los docentes y los estudiantes, vinculada con la capacidad de escucha de los docentes.

2 Se alude aquí al planteo de Schön $(1992 ; 1998)$ acerca de los tres niveles de reflexión que discrimina el autor en relación con las prácticas profesionales: la acción profesional misma, la reflexión en la acción y la reflexión sobre la acción. Estos niveles están determinados, entre otros elementos, por la relación que se establece entre los saberes y el tiempo en que se conjugan. 
- El tipo de saberes que se jerarquizan (didácticos, disciplinares, morales o filosóficos, del sentido común, contextuales, de la experiencia, de su formación escolar anterior, de su formación para la docencia, entre otros), y la manera en que el manejo que se propone de estos impacta en el alcance de la reflexión.

- $\quad$ El tipo de preguntas que se plantean: abiertas, pero no demasiado amplias para que den lugar a la elaboración; o interrogantes demasiado cerrados que restringen la reflexión.

- Las experiencias de los docentes durante su formación para la docencia, exponiendo sus propias prácticas de formación como puntos de referencia positivos o negativos, constituyéndose en experiencias identificatorias $\mathrm{o}$ contraidentificatorias.

Estos hallazgos se reconocen como relevantes en la configuración de la orientación o tutoría de las prácticas; en especial, en lo que concierne al análisis de estas; sin embargo, no se desarrollan aquí porque se entiende que exceden el planteo que se pretende en este trabajo.

A modo de cierre y en primer término, como cuestión evidente, reafirmamos que la experiencia de la observación está marcada por la subjetividad. En particular, por imágenes preexistentes en la memoria del observador, las cuales establecen un diálogo con las que son observadas en el tiempo presente. En ese sentido hay una huella marcada por el tiempo en cuanto a las condiciones que este le otorga a la observación. Lo efimero del presente y la imposibilidad de registrarlo en toda su complejidad representan cuestiones que determinan una reconstrucción imposible de los hechos en el tiempo sellado.

En segundo término, se plantea la idea de reconocer la perspectiva que nos propone el arte en cuanto a la experiencia de la observación y la necesidad de habilitar cierta condición previa de prestar atención para poder analizar. En otras palabras, la pertinencia de recuperar una mirada gentil, desprovista de juicios en una primera instancia al observar una clase, considerándola desde su naturale- za única y singular, permitiendo que las imágenes se revelen y las miradas se renueven, poniendo a prueba los prejuicios y creencias para generar un análisis profundo sobre lo que se observa, desde una perspectiva multirreferencial, ${ }^{3}$ dando lugar a movilizaciones de experiencias y sentidos. Como dice Edelstein (2011), intentando desandar la huella que nos ha dejado el ámbito de las instituciones educativas y los espacios de formación docente sobre la observación de las prácticas asociadas al control y a la sanción. En este sentido, reconocemos la necesidad de proponer una nueva formación para des-aprender a mirar, analizar y comprender diferentes situaciones pedagógicas.

Por último, parece pertinente recordar que, en cualquier caso, el proceso de observación y análisis de las prácticas solo cobra sentido cuando constituye un intento de reconstrucción crítica en clave propia para los protagonistas de la escena; en particular, para quien desarrolla su práctica docente, como una apuesta a la comprensión y al estudio de las prácticas.

3 El análisis multirreferencial planteado por Souto $(1998 ; 2017)$ refiere al abordaje del análisis de las prácticas pedagógicas desde diversas perspectivas disciplinares y teóricas, cada una con su leguaje, con su construcción específica y modos de abordaje, los que deben ser respetados, pero que también deben buscar articulaciones posibles en el intento de superar miradas fragmentadas. Este tipo de análisis pone en juego un doble proceso de comprensión, «se busca desde el adentro de los sucesos y no desde una posición desde exterioridad [...]. La referencia a las teorías surge de la comprensión de los datos mismos. Ellos piden la referencia teórica necesaria para su elucidación» (Souto, 2017: 180).

\section{Referencias bibliográficas}

Andreozzi, M. (1996). El impacto formativo de la práctica. Revista del Instituto de Investigaciones en Ciencias de la Educación, 5 (9). Buenos Aires: Miño y Dávila, 20-31.

- (1998). Sobre residencias, pasantías y prácticas de ensayo. Revista del Instituto de Investigaciones en Ciencias de la Educación, 7 (13). Buenos Aires: Miño y Dávila, 33-43.

Bourdieu, P. (1980). El sentido práctico. Buenos Aires: Siglo XXI Editores.

Davini, M. C. (2015). La formación en la práctica docente. Buenos Aires: Paidós.

Edelstein, G. (2011). Formar y formarse en la enseñanza. Buenos Aires: Paidós.

Gombrich, E. (2004 [1999]). Breve historia del arte (11. a ed.). Barcelona: PenínsulaAtalaya.

Lores, A. (1986). Epistemología de las ciencias sociales. Buenos Aires: De Belgrano.

PAstorino, I. (2015). La configuración de la orientación en la práctica docente universitaria: el caso del ISEF (tesis de maestría).

Universidad de la República, Uruguay. Disponible en 〈http://www.cse.udelar.edu.uy/tesis-meu/>.

raeasale (2014). Diccionario de la lengua española (23. ${ }^{a}$ ed.). Consultado en «www.rae.es〉.

Schön, D. (1992). La formación de los profesionales reflexivos. Barcelona: Paidós.

- (1998). El profesional reflexivo: cómo piensan los profesionales cuando actúan. Barcelona: Paidós.

Souto, M. (2017). Los pliegues de la formación. Sentidos y herramientas para la formación docente. Rosario: Homo Sapiens.

TARKovski, A. (2017 [1991]). Esculpir en el tiempo (14. ${ }^{a}$ ed.) Madrid: Rialp.

WeIL, S. (2007 [1947]). La gravedad y la gracia (4a ed.) Madrid:Trotta. 